International Journal of Health Sciences
Available online at www.sciencescholar.us
Vol. 5 No. 2, August 2021, pages: vi-ix
e-ISSN: 2550-696X, p-ISSN: 2550-6978
https://doi.org/10.53730/ijhs.v5n2.2937

\title{
The COVID-19 Pandemic
}

\author{
(D) crossark \\ I Wayan Suryasa a, María Rodríguez-Gámez ${ }^{\text {b }}$, Tihnov Koldoris ${ }^{\mathrm{c}}$
}

\section{Editorial}

\section{Keywords}

cardiovascular disease;

COVID-19;

health education;

mental health;

pandemic;

pneumonia;

public health measure;

respiratory problems;

Sars-Co-2;

\begin{abstract}
Humanity has been on its way accompanied by epidemics, as man has evolved, he has faced different problems that have affected most of society. In the last 50 years, more viruses have appeared that have affected different regions and multiple countries; but one of the most distributed worldwide is COVID-19. The objective is to offer some information related to this pandemic and its evolution in different countries. The bibliographic review method was used even though some bibliographies are very recent, but it has allowed us to know their behavior and follow-up. The results of the countries most affected by this pandemic are shown, where it could be said that Italy has increasingly affected all of them and some countries in Asia, the United States, Latin America, and the Caribbean have been the most affected.
\end{abstract}

International Journal of Health Sciences (C) 2021. This is an open access article under the CC BY-NC-ND license (https://creativecommons.org/licenses/by-nc-nd/4.0/).

\section{Introduction}

At the present time one of the most contagious in history is going through, the current pandemic produced by the SARS-CoV-2 influenza virus, coronavirus. Cause of the pandemic is named by the World Health Organization as COVID-19 (PAHO, 2020). The characterization now of pandemic means that the epidemic has spread to several countries, continents, or the whole world, and that it affects many people, which even today continues to affect mainly Europe. One of the most serious problems that the transmission currently causes is citizen irresponsibility, first many do not want to be vaccinated and others because they do not use the means of protection (Bansal, 2020; Perret-Guillaume et al., 2009; O'Loughlin et al., 1999). Governments must take measures to help curb this situation, considering the new Omicron variant, it is so dangerous due to its rapid spread that it is already in the community transmission phase, for example in New York (WORLD, 2021).

\footnotetext{
a ITB STIKOM Bali, Denpasar, Indonesia

b Universidad Técnica de Manabí, Portoviejo, Ecuador

c Queen Mary University of London, London, United Kingdom
} 
One of the difficulties of COVID-19 is the condition that it has caused in the mental health of the population. The world is experiencing an exceptional situation due to the advance of the pandemic and now with its new variant of the Omicron it has not allowed the full recovery of some countries (Mehanna \& Jankovic, 2010; Mellies \& Lofaso, 2009). Many regions are in the alert phase, this severe acute respiratory syndrome that requires preventive and compulsory social isolation, has generated a psychosocial impact on humanity (Ribot, Chang, \& González, 2020). Some news suggest that this variant is highly transmissible, in addition to not having achieved a massive vaccination at the planetary level, where many people were not vaccinated in the first stage, different viral variables can be produced (BBC, 2021), which is what is happening.

The Pan American Health Organization (PAHO) reports that the variant that appears most frequently is the Delta, and since it was first notified in July 2020, 181 countries around the world - including 54 countries and territories of the Americas have notified their detection (PAHO, 2021), this organization recommends continuing efforts to increase vaccination coverage against COVID-19 and improve adherence to public health measures that reduce the transmission of the SARS-CoV-2 virus (Romero et al., 2021; Wang et al., 2021). It also calls on countries to continue genomic sequencing of samples and to monitor changes in the incidence of COVID-19. Current PCR tests can detect Omicron and the other variants (MUNDO, 2021). Vaccination remains essential to reduce the frequency of disease and deaths, even in the case of the delta variant, which is currently the dominant variant. All the vaccines currently used continue to prevent me very effectively handle severe symptoms and death from COVID-19 (Arimbawa et al., 2021).

The World Health Organization recommends increasing surveillance and sequencing of samples taken from cases; exchange genomic sequences in open databases, carry out field studies and analytical evaluations to better understand whether the omicron variant has different characteristics in terms of its transmissibility and the disease it causes or affects the efficacy of vaccines, treatments, diagnostic tests or social and public health measures (Jiang et al., 2020; Lin et al., 2020; Fine et al., 1990). As you have noticed, different variants have been developed worldwide, the Delta that appeared in India and was later transmitted to America and now we have the Omicron that is currently advancing in a very progressive way, and they are studying this variant is more contagious than the Delta.

Scientists suggest that the ability to predict an emerging variant of SARS-CoV-2 on the global scene can help in the evaluation of medical countermeasures and non-pharmaceutical interventions (Dong, 2021), according to them the data that can be collected can suggest predicting the emergence of a new variant based on tracking the distribution and frequency of minor variant genomes at the population level, rather than simply focusing on providing information on the dominant viral genome sequence, eg, consensus-level reports (Velázquez et al., 2021). The ability to predict an emerging variant of SARS-CoV-2 in the world can aid in the evaluation of medical and non-pharmaceutical countermeasures in treatments. It is commendable to acknowledge WHO's work with Governments and other partners to rapidly expand scientific knowledge on this new virus, track its spread and virulence, and advise countries and individuals on measures to protect health and prevent its spread

\section{Recommendations}

The committee, editorial recommends complying with the WHO indications, applying the most effective measures that everyone can take to reduce the spread of the virus that causes COVID-19 by keeping a distance of at least one meter from other people, wear a mask tightly fitting, open windows to ventilate rooms, avoid crowded or poorly ventilated places, keep hands clean, cough and sneeze into the elbow flexure or into a disposable tissue, and get vaccinated when their turn comes.

\section{Acknowledgments}

We would also like to express our gratitude to all the contributors, namely the authors, reviewers, and editors, who have made this issue possible. IJHS is currently accepting manuscripts for upcoming issues based on original qualitative or quantitative research that opens new areas of inquiry and investigation.

Suryasa, I. W., Rodríguez-Gámez, M., \& Koldoris, T. (2021). The COVID-19 pandemic. 


\section{References}

Arimbawa, . I. M., Paramita, A. D. P., Nuaba, I. G. A., \& Saputra, H. (2021). Management of hypocalcemia after modified bilateral radical neck dissection followed with total thyroidectomy: a case report. International Journal of Health Sciences, 5(1), 9-19. https://doi.org/10.29332/ijhs.v5n1.654

Bansal, M. (2020). Cardiovascular disease and COVID-19. Diabetes \& Metabolic Syndrome: Clinical Research \& Reviews, 14(3), 247-250. https://doi.org/10.1016/j.dsx.2020.03.013

BBC. (2021). Covid: When people do not have immunity, they are variant factories.

Dong, X. Y. (2021). Rapid selection of P323L on SARS-CoV-2 polymerase (NSP12) in human and non-human primate models confers a large plaque phenotype. Cold Spring Harbor Laboratory (bioRXiv).

Fine, M. J., Smith, D. N., \& Singer, D. E. (1990). Hospitalization decision in patients with community-acquired pneumonia: a prospective cohort study. The American journal of medicine, 89(6), 713-721. https://doi.org/10.1016/0002-9343(90)90211-U

Jiang, X., Deng, L., Zhu, Y., Ji, H., Tao, L., Liu, L., ... \& Ji, W. (2020). Psychological crisis intervention during the outbreak period of new coronavirus pneumonia from experience in Shanghai. Psychiatry research, 286, 112903. https://doi.org/10.1016/j.psychres.2020.112903

Lin, C., Ding, Y., Xie, B., Sun, Z., Li, X., Chen, Z., \& Niu, M. (2020). Asymptomatic novel coronavirus pneumonia patient outside Wuhan: the value of CT images in the course of the disease. Clinical imaging, 63, 7-9. https://doi.org/10.1016/j.clinimag.2020.02.008

Mehanna, R., \& Jankovic, J. (2010). Respiratory problems in neurologic movement disorders. Parkinsonism \& related disorders, 16(10), 628-638. https://doi.org/10.1016/j.parkreldis.2010.07.004

Mellies, U., \& Lofaso, F. (2009). Pompe disease: a neuromuscular disease with respiratory muscle involvement. Respiratory medicine, 103(4), 477-484. https://doi.org/10.1016/j.rmed.2008.12.009

MUNDO, E. (2021). Omicron variant is widely dominant in the US.

O'Loughlin, J., Masson, P., Déry, V., \& Fagnan, D. (1999). The role of community pharmacists in health education and disease prevention: a survey of their interests and needs in relation to cardiovascular disease. Preventive medicine, 28(3), 324-331. https://doi.org/10.1006/pmed.1998.0436

PAHO. (2021, December). Omicron and other variants of concern identified in the Americas.

Perret-Guillaume, C., Joly, L., \& Benetos, A. (2009). Heart rate as a risk factor for cardiovascular disease. Progress in cardiovascular diseases, 52(1), 6-10. https://doi.org/10.1016/j.pcad.2009.05.003

Ribot, V., Chang, N., \& González, A. (2020). Effects of COVID-19 on the mental health of the population. Habanera Magazine of Medical Sciences, 19(1).

Romero, M. D. C. V., Cárdenas, A. M., Fuentes, A. B., Barragán, A. A. S., Gómez, D. B. S., \& Jiménez, M. T. (2021). Acute mesenteric arterial thrombosis in severe SARS-Co-2 patient: A case report and literature review. International Journal of Surgery Case Reports, 86, 106307. https://doi.org/10.1016/j.ijscr.2021.106307

Velázquez, M. del R. H., Báez, A. A. L., Pérez, A. M., \& Luna, A. A. (2021). Educational innovation in the comprehensive training of nursing graduates. International Journal of Health Sciences, 5(1), 20-28. https://doi.org/10.29332/ijhs.v5n1.700

Wang, P., Casner, R. G., Nair, M. S., Wang, M., Yu, J., Cerutti, G., ... \& Ho, D. D. (2021). Increased resistance of SARS-CoV-2 variant P. 1 to antibody neutralization. Cell host \& microbe, 29(5), 747-751. https://doi.org/10.1016/j.chom.2021.04.007 


\section{Biography of Editors}

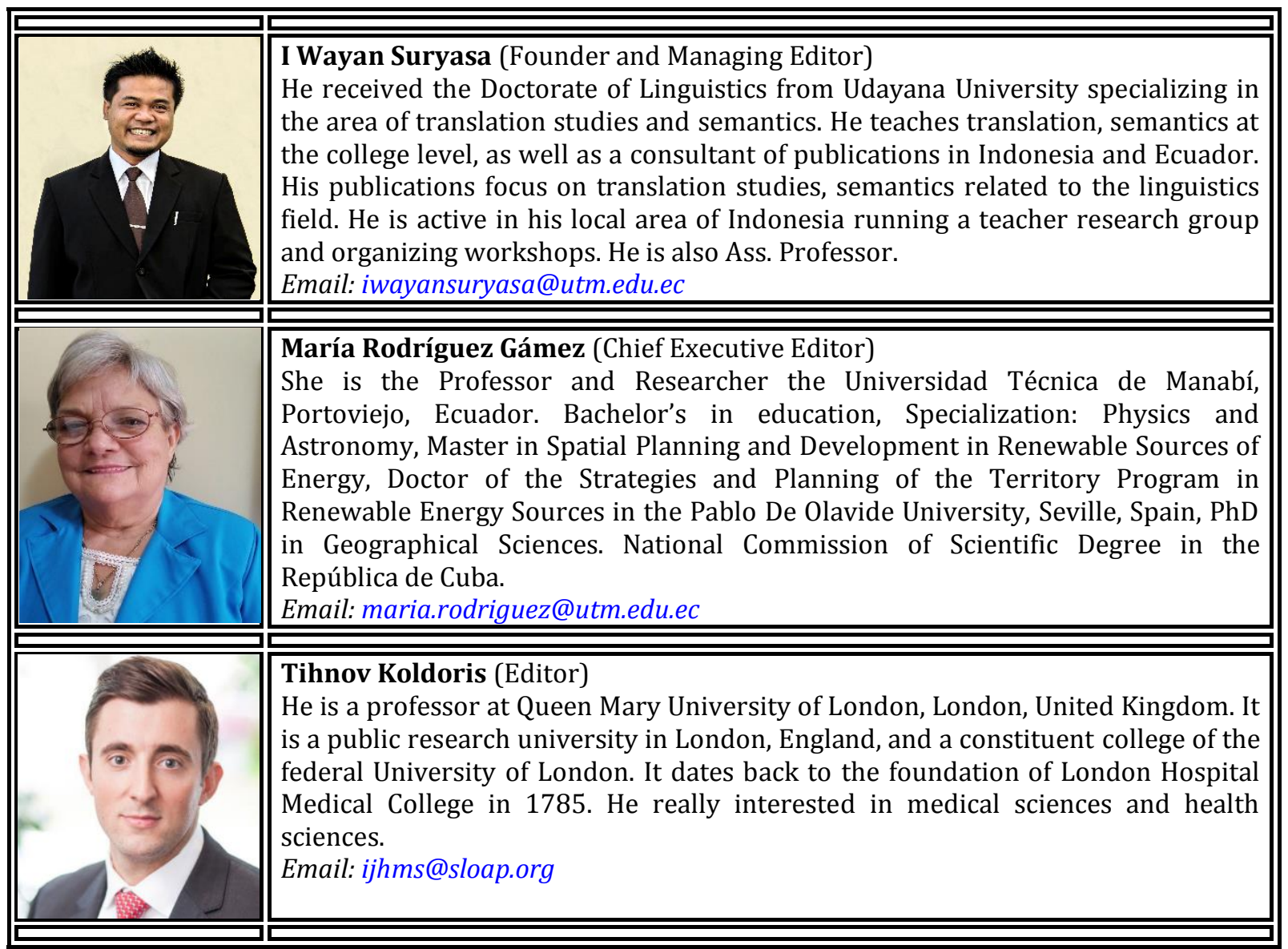

Suryasa, I. W., Rodríguez-Gámez, M., \& Koldoris, T. (2021). The COVID-19 pandemic. International Journal of Health Sciences, 5(2), vi-ix. https://doi.org/10.53730/ijhs.v5n2.2937 